\section{CLINICAL ETHICS CONSULTATION: ATTENTION TO CULTURAL AND HISTORIC CONTEXT}

\author{
Stuart J. Youngner \\ $M D$ \\ Susan E. Watson \\ Professor and Chair, Department of Bioethics \\ Case Western Reserve University
}

\begin{abstract}
RESUMEN: La Consulta Ética Clínica es una actividad relativamente nueva en USA, como un servicio destinado a ayudar a pacientes individuales o grupos. Se describe la evolución histórica de la CEC desde su inicio en 1976. Entre otras funciones, la CEC presta un soporte moral y un "confort" psicológico a los profesionales de la salud en la toma de decisiones. Se describen los métodos operativos y de acceso a la CEC.
\end{abstract}

PALABRAS CLAVE: Consulta Ética Clínica (CEC), bioética, derechos de los animales, negligencias, soporte moral, confort psicológico.

Clinical Ethics Consultation is a relatively new activity in the United States. It is still in evolution and, therefore, its shape and impact remain somewhat ill defined. Ethics consultation falls in the category of clinical ethics which itself may be subsumed under the broader category of bioethics. Bioethics deals with moral dimensions of bioscience, including topics ranging from scientific misconduct and animal rights to distributive justice in health care. One of the more focused areas included in bioethics is clinical ethics, an area that considers the moral dimensions of the provision of clinical care. It could include such subjects as truthtelling, confidentiality, euthanasia, applications of reproductive technology or genetic counseling. Clinical ethics consultation involves a specific practical application - indeed a clinical practice - in the realm of clinical ethics.

The recent Report of the American Society for Bioethics and Humanities, "Core Competencies for Health Care Ethics Consultation," defined clinical ethics consultation as:

A service provided by an individual or a group to help patients, families, surrogates, health care providers, or other

\section{CONSULTA ÉTICA CLÍNICA: ATENCIÓN AL CONTEXTO CULTURAL E HISTÓRICO}

ABSTRACT: The clinical ethics consultation is a relatively new activity in US; a sort of service set aside for helping individual patients and groups. The historical evolution of CEC is described from the very beginning to 1976. Among other duties CEC gives moral support and psychological comfort to professionals related to health in decision-making moments. The operative methods and the access systems to CEC are fully described.

KEY WORDS: Clinical Ethics Consultation (CEC), bioethics, animal rights, malpractice, moral support, psychological comfort.

involved parties address uncertainty or conflict regarding value-laden issues that emerge in health care ${ }^{1}$.

The Report considered two "domains" of consultation: 1) clinical ethics, issues that arise in specific patient cases; and, 2) organization ethics, which addresses the corporate and business practices of health care organizations. I will deal here only with the first, touching briefly, if at all, on the newer and highly controversial issue of organizational ethics. First, I will trace the history of the development of clinical ethics consultation (CEC) in order to demonstrate how it was shaped by the unique scientific, social, and legal context in the United States in the last third of the $20^{\text {th }}$ century - especially the evolving notion of patient autonomy. Next I will address some special features of CEC:

- The competing or complementary roles CEC might be tempted by or pressured into;

- The proper approach. Authoritarian, pure facilitation/ mediation, or the so-called ethics facilitation model? 
-Who should have access to ethics committees (perhaps the most controversial issue of all).

- How is it best done. By committee, small team, or individual consultant?

I will argue that CEC must, by definition, be a practice that "intrudes" into clinical practice in the sense that it does something that was not done before that has the potential to affect clinical decisions and, therefore, clinical outcomes. How it affects clinical practice may be viewed positively or negatively, may be welcomed or rejected, may be effective, useless, or even destructive. Because of this reality, how CEC is practiced and received will be highly dependent on the particular social, political, religious, and legal context. It will inevitably address and effect: the nature of hierarchical relationships (e.g., physicians with nurses, professors with trainees); the control of medical information; the right and responsibility for medical decisions; and, the differences in values and expectations between the important players (patient, family, health professionals, institution).

It is inevitable that CEC will have a very different face, if it shows its face at all, in clinical cultures that are very different. CEC is different on surgery services than it is in pediatrics. The differences will be more dramatic when we move from different services to different communities and, certainly, to different countries and regions of the world. Therefore, the way CEC is done in North America can serve only as an example, not a model, for how it might be done in other cultures. Nonetheless, I believe common issues exist in all cultures and that at some level, uncertainty exists about how to resolve them-for example, the control of medical information and the proper time to forego aggressive life-sustaining treatment. As technology and cultural diversity magnifies the areas of uncertainty throughout the developed world, CEC may have something to offer.

\section{THE History OF CEC}

We shall see in a later section of this paper that ethics committees are not the only, or, necessarily, the best way to deliver CEC. But ethics committees were historically the first way that grabbed public attention. In the 1960s renal dialysis first became widely used in the United States.
However, there were many more persons with end-stage renal failure who were referred to dialysis than there were dialysis machines. Dialysis had to be rationed so hospitals formed committees to choose who would live and who would be allowed to die. Committee members were largely white race, men, and upper-middle class. The values that guided their decisions, not surprisingly, were ones that, by and large, ensured that persons similar to themselves would be selected. There was a national outcry about this state of affairs. Selection committees were derisively referred to by the lay press as, "God Squads." The committees ceased to function when the cost of dialysis was covered by the government in 1973. But they had introduced the American public to the notion of ethics committees in hospitals.

The next major public attention to ethics committees came in 1976 in the case of Karen Quinlan, a woman in her 20s who had suffered severe brain injury and had no likelihood of recovery. The case had attracted a great deal of national attention because the patient was being kept alive by a mechanical ventilator, a new technology at that time. The nation had little clinical, legal, or social experience with turning off ventilators. Was it illegal? Could people be charged and convicted of murder? Or, was it reasonable under the circumstances? The national discussion ended when the New Jersey Supreme Court ruled that the parents could require physicians and the hospital to turn off the ventilator and allow Karen Quinlan to die. In its written opinion, the court mentioned that hospital ethics committees might be helpful in resolving such difficult issues.

At about this time, my own hospital opened its first intensive care units in medicine, surgery, pediatrics, and neonatology. It became impossible to ignore the question of when it was permissible to stop life-sustaining interventions. The directors of these various intensive care units got together and decided to form a committee, an ethics committee, where they could bring difficult cases for discussion with knowledgeable colleagues including nurses, social workers, and clergy.

By 1981, only about $1 \%$ of hospitals in the United States had formed such committees, but the problems of discontinuing life-sustaining treatment were growing in number and complexity². Many cases were taken to court for resolution, but the expense in time, energy, money, and 
mental anguish made such action undesirable. That ethics committees might serve as a first alternative for resolving disputes was an alternative strongly suggested by a prestigious President's Commission in the early 1980s. In fact, the number of ethics committees increased so that today they are estimated to exist in a vast majority of health care institutions ${ }^{3}$. Moreover, the Joint Commission on Accreditation of Healthcare Organizations (JCAHO), which accredits hospitals and nursing homes, requires that all health care institutions must have formal mechanisms for resolving ethical disputes and that these mechanisms be explicitly available to patients, families, and health professionals. Moreover, hospitals must have written policies about ethics-related matters such as turning off life-sustaining machines, do-not-resuscitate orders, and informed consent to treatment.

Ethics committees and CEC were (and still are) resisted, primarily by physicians who viewed them as unwanted intrusions into the physician/patient relationship. CEC was seen by many as unnecessary at best, and disruptive and even seditious at worst. In the face of such strong resistance, how then did CEC become so widespread? The answer lies in a social movement that coincided with and paved the way for CEC.

In the United States in the 1960s and early 1970s there was a virtual human rights revolution. This revolution challenged traditional hierarchical structures of government, social institutions (such as schools and hospitals) and human relations (such as those between teacher and student and between physician and patient). It included African Americans, women, homosexuals, prisoners, students, consumers of various products such as automobiles, and, finally, patients. The revolution stressed the importance of individual autonomy and the right of individual members of society to pursue "life, liberty, and the pursuit of happiness." Such a right entailed access to public goods such as housing, schools, and jobs, but also the right of individuals to information and the control of decisions that affected their lives. Often, the full pursuit of such rights challenged the authority of police, teachers, physicians, and males who had enjoyed special privilege and trust by virtue of their professional, racial, or sexual status. Sometimes there were demands for financial redress or even criminal punishment for what had been "accepted" practice but a decade before.
In medicine, lawyers began suing physicians who failed to inform patients about their options or made damaging mistakes in their care. Coincident with this rights movement was the explosion in medical technology. Technology dramatically increased control over the timing of death. Patients and families began demanding the "right to die" by refusing life-sustaining treatment. Health professionals and hospitals for the most part resisted, but the judges in the court system repeatedly supported the notion that patients or their surrogates have a right to determine such choices ${ }^{1}$. If CEC entered hospitals against the will, or at least without the support, of most health professionals, it did so only because the legal and government regulatory system had paved the way. In fact, while many physicians and hospitals saw ethics committees as intrusive, they found them much less so than malpractice attorneys, judges, and government regulators. In cultures where the "rights movement" was not so robust or has yet to occur at all, resistance to CEC will be greater than it was in the United States. We shall see, that even in the United States, with its emphasis on patient rights and autonomy, the functioning of CEC has been shaped and restricted in ways that continue to protect traditional power structures.

\section{Conflicting and Secondary Roles}

Modern health care facilities are complicated places that face a number of social, economic, legal, and regulatory problems. While it is important to recognize and address those problems, CEC is not and should not be the primary way to deal with them, although some persons may wish and others fear that CEC will assume the role of doing so. Let us examine some examples.

In the United States concerns about malpractice law suits is ubiquitous. Physicians and hospitals are regularly sued for malpractice, a tremendous expenditure of time, energy, and money. Studies have repeatedly demonstrated that law suits are much more likely when there is poor communication. Since one benefit of CEC is enhanced communication, it stands to reason that $\mathrm{CEC}$ might reduce the number of law suits. I believe it does so, but I reject the notion that reduction of law suits (called "risk management') is the primary role of CEC because there are times when doing the right thing from a moral perspective may, in fact, not 
be the right thing to do from the risk management perspective. If we think, and I will so argue, that CEC's primary role is to facilitate doing the morally right thing, it's primary goal should never be risk management. In the United States, hospitals have entire departments devoted to risk management for reasons that are quite understandable. But if CEC takes risk management as its primary role, it will have little credibility within the institution and society.

Health care facilities, as representative of the larger society in which they exist, are also places where truly evil things sometimes happen. Patients may be physically or sexually abused. The power of physicians in the medical hierarchy gives them the opportunity to abuse that power to take advantage, not only of patients and their families, but other health professionals. Such unacceptable behavior should be identified, stopped, and guilty parties punished, but the role of detective and policeman is not suited for CEC. Finding and stopping major moral and even criminal problems is the responsibility of institutional administrative structures such as department chairmen, chiefs of staff, or chief executive officers. Terrible breaches of morality and the law need to be investigated and stopped, but if those with true power in institutions are unwilling or unable to deal with them, CEC certainly will not be able to do so.

Indeed, if CEC functions as detective (unilaterally looking around for and investigating major moral infractions) and policeman (stopping and punishing the perpetrators), it will be feared and avoided. The problems best suited to CEC are those less dangerous and dramatic issues where reasonable people disagree about the right course of action and where open discussion, sharing of information, and respect for differences are helpful. They are problems where people voluntarily seek help. Taking on a detective or police function by CEC will ensure that no one asks for the help of CEC in resolving everyday moral problems. And, no one will want to be associated with it (just as few people want their neighbors to see a squad of policemen visiting their home). In fact, persons doing CEC often must convince their potential constituents that they do not function as intrusive law enforcement.

The presence of CEC in health care institutions may also serve a useful public relations function. If the public is concerned about how well their rights will be protected in hospitals and nursing homes, the well-advertised presence of an ethics committee or ethics consultation service might be reassuring. This function is a reasonable one, but like risk management, should always be secondary. CEC should not serve as a moral "cover" while its ability to function properly in an institution is, for all intents and purposes, non existent.

Persons doing CEC can also do some of the duties of social workers (helping families in crisis), persons concerned with quality of care, or even cost savings, but I would argue that although these secondary roles are sometime helpful, there are others persons trained for them specifically. They should never be the primary role of CEC.

One function of CEC is to provide moral support and psychological comfort for health professionals facing difficult moral decisions. This is a legitimate and useful function, but, again, should not be the primary one. There are times when it will be the job of CEC to makes health professionals more uncomfortable by bringing to their attention complexities that had been ignored or sidestepped.

Some persons in the United States have argued that CEC should function as patient advocate - that is, the primary role of ethics committees or consultants should be to protect the rights and autonomy of patients. In American culture, patient autonomy remains, perhaps, the most powerful principle guiding ethical decisions and should always take a prominent place in discussions initiated by CEC. However, there are other important moral principles to be considered, such as beneficence and nonmaleficence (the duty to help and not to harm) that in some cases are equally or even more relevant to understanding and helping. There is certainly a need for patients rights to be protected but most hospitals in the United States have specifically designated persons to function solely as patient advocates. Patients may also have access to lawyers who can serve that function. Is it not the responsibility of every physician, nurse, social worker, and administrator to advocate and protect the rights of patients? Moreover, rights language tends to be confrontational, demanding, and often encourages conflict rather than discussion with a view to compromise and resolution.

By making patient advocacy the guiding principle behind CEC functioning, we force it into an unrealistic and un- 
wanted role. As we shall see in the next sections, taking that role seriously would pit CEC against the political power structure of health care institutions and the real balance of power in the physician/patient relationships. Even if one argues that this structure and balance of power should be changed (and it is not clear that most patients want this), the role of political revolutionary would render CEC even more ineffective and marginalized than that of policeman.

As mentioned above, the Report of the American Society for Bioethics and Humanities defined the role of CEC as: a service provided by an individual or a group to help patients, families, surrogates, health care providers, or other involved parties address uncertainty or conflict regarding value-laden issues that emerge in health care ${ }^{1}$.

The Report goes on to advocate an "ethics facilitation model" which recognizes that CEC takes place in a culture that has two important features. The first is that in the United States, as in any culture, there are some clearly delineated boundaries between morally acceptable and unacceptable behavior. Usually, but not always, these boundaries are echoed in the law. The second is that we live in a liberal democracy that accepts a plurality of values and endorses and, indeed protects, the rights of individuals to live by their own moral values. To one degree or another, all western democracies share this perspective.

Therefore, the Report rejects an "authoritative" role for CEC. The ethics consultant should not function as philosopher king, or priest. He/she is not the repository of the moral truth or law which can be handed down at the expense of the appropriate moral decision makers (patient, family, health professionals). But the Report also rejects a "pure facilitation" model in which the only goal is to forge consensus no matter what the outcome. CEC also has a responsibility to identify and explain the areas of moral consensus within the society and the institution - for example, that a physician may not actively kill a patient or that in a Roman Catholic hospital, abortion is not an acceptable option. In my culture, CEC has a responsibility to actively advocate for the right of competent patients (who so wish) to control the decisions about their care. In societies where that right was not clearly established, the responsibility to advocate for it would be much diminished. It is, of course, with very controversial issues or ones where social values are in the process of change, that the delineation between the role as interpreter of society's agreed upon values and mere facilitator becomes most difficult.

\section{Method of Operation and Access to CEC}

The issue of access to and operation of CEC is where, as automobile-crazy Americans like to say, "the rubber hits the road." CEC is least threatening to traditional power structures when the case review is retrospective. More intrusive is prospective review in which CEC becomes actively involved in case before final decisions are made. Most CEC done in the United States is prospective.

Another dimension in operation is whether the consultation is mandatory or voluntary. That is, can the person(s) doing CEC decide unilaterally to become involved in a case, or should they wait to be invited in. A third dimension regards the opinion of the consultant or committee. Is it binding, in the sense that patients, families, and health professionals must follow it as an order, or is it voluntary, they may take or leave it as a recommendation. A system that allowed CEC to impose itself and that demanded its opinions be obeyed would definitely go against the stream and place CEC in the role of detective and policeman or judge rejected earlier in this paper. Therefore, almost all CEC done in the United States in voluntary in regard to both involvement and opinion.

Access to the services of CEC is another controversial issue where political reality often takes precedent over ethical theory ${ }^{4}$. There are several levels of access:

1. Knowledge about the existence and rules governing CEC;

2. Ability to request or veto $\mathrm{CEC}$;

3. Notification that CEC is taking place;

4. Ability to participate in CEC;

5. Awareness of CEC deliberations and recommendations.

ARBOR CLXXXIV 730 marzo-abril [2008] 285-292 ISSN: 0210-1963

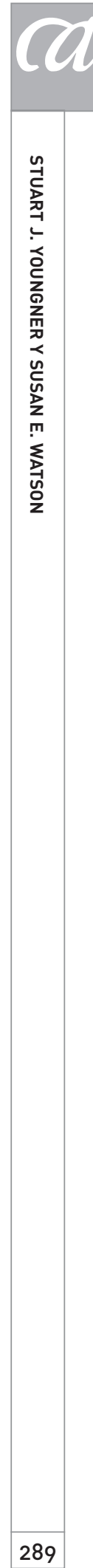


Extreme patient rights advocates insist that patient and families have maximum control of the CEC process while traditional, paternalistic physicians claim that only the physician "in charge" should control it. In the United States, when CEC first entered health care institutions, patients, families and health professionals other than senior physicians had very little access to and control over the CEC process. That has slowly changed but still, CEC remains a health professional and, largely, physician-guided process. This may not coincide with the pure idealism of patient rights, but it reflects the changing, but not yet fully changed, nature of power relationships and expectations in the practice of medicine and the delivery of health care.

If patients and their families do not even know of the existence of CEC in an institution or how it functions, they can be effectively excluded from the rest of its functioning. If you do not know it exists, you can not request it or insist on participating in it and being informed of its outcome.

Who should be allowed to request CEC? Certainly, other medical consultations are controlled by the patient's primary physician. Patients rarely if ever directly call in cardiologists or surgeons without the participation and permission of their primary physician. But CEC is different precisely because it often deals with challenges to the moral authority of health professionals or institutions by patients or their families. If patients do not know that a hospital has CEC available and how it works, they are being told that they are at best a passive part of the process. If patients do not know that an ethics consultation is taking place, their right and authority to participate in decisions that effect their lives is further attenuated. If they are not allowed to request CEC directly, they are being further marginalized in a paternalistic system. The same is true for nurses and other physicians - for example, trainees like residents. If physicians or hospital administrators view CEC as performing a detective or police function, this is understandable. However, the ethics facilitation model insists merely on open discussion, sharing of data, and adherence to clearly delineated social norms. Categorical refusal to allow any person with a moral stake in the case to participate by requesting, joining in the conversation, and being informed about the results is a form of moral paternalism unacceptable in a liberal democracy.
In fact, although we inform patients and families about the availability of CEC, patients rarely ask for it, although, in my institution, residents and nurses do so frequently. We always ask patients, families, and other medical staff if they have discussed the problem and the request for CEC with the attending physician (the physician ultimately responsible for the case) and, if they have not, suggest they do so before we become involved. We do not want to provide an easy avoidance of direct and constructive discussion within the health care team. When they initiate the conversation, the need for CEC often disappears. Attending physicians, when asked, have rarely refused the consultation. When they do so, it has always represented a worrisome breakdown in communication between health professionals or between the physician and the patient. Such breakdowns are better managed by risk managers, patient advocates, or the administrative structure of the hospital, groups that have primary responsibility for these matters and clear authority and power to deal with them.

Each institution and each society that uses CEC will have to strike the right balance about the access issue, a balance that must take into account the prevailing moral consensus about the rights of patients, families, and other members of the health care team as well as the structure of power in that particular setting. As the society or institutional culture evolves, changes can be instituted that reflect this evolution. Forcing issues is rarely, if ever, successful in this context.

\section{How is CEC Best Accomplished-by Committee, Small Teams, or Individual Ethics Consultants?}

In the United States, CEC has been and continues to be performed in three distinct ways - by committee, by small teams, and by individual consultants. Each method has its own advantages and disadvantages ${ }^{5}$.

Ethics committees are, perhaps, the best known. Traditionally, ethics committees include representatives of various professions within the health care setting such as physicians, nurses, social workers, hospital lawyers, clergy and, often, one or two representatives from the lay public. Of course, early in their evolution, many ethics committees 
included only physicians, but that has largely changed. Most often, ethics committees function like an administrative body. They meet only one time, hear clinical and social data presented most often by the attending physician supplemented by other health professionals and make their recommendations at that single meeting to be included in the medical record or shared with the patient and family at the discretion of the attending physician. Critics of this method point out that ethics committees are not "user friendly." For example, it is difficult to get a group of busy people together for a meeting at short notice. The formal nature of a committee meeting with a room full of people can be intimidating, making it less likely that people will call or participate in a meeting. This is particularly true for patients and families who are likely to feel overwhelmed by a room full of strangers. Ethics committee members obtain information second or third hand and have little or no opportunity to gather more information if it is needed. Some people have cautioned that responsibility will be diffused when it rests with a group of people and that committee deliberations will lead to "groupthink" - the tendency of groups to seek agreement rather than take on difficult issues.

Proponents of ethics committees argue that committees are more likely to fulfill the democratic ideal of ethics facilitation because many values and points of view will be represented by multiple committee members as opposed to an individual consultant, who may be more prone to act like a philosopher king, imposing his or her unique values.

Ethics committees also give more institutional "ownership" to ethics problems and their solutions rather than vesting them in one expert. Education about the ethical problems in the institution is also more widespread when committees are involved.

Proponents of individual ethics consultants point out how much more user friendly they are. A single consultant is much more available for informal or emergency consultation. He or she can gather relevant facts directly from the medical record and conversations with the relevant parties - patients, families, and health professionals. Because of its more informal nature, CEC done by individuals can more naturally involve patients and families in the process. CEC is an ongoing process, it is argued, not a single event. An individual consultant can collect data over time, revisit conversations after more information becomes available and get important parties together for discussion and conflict resolution whenever necessary. Committees tend to conduct their business in a single meeting. A single consultant is visible to all concerned and can write a note directly in the patient record, allowing maximum accountability. In my own experience, when our hospital went from the committee to the individual consultant model, the number of consults requested increased by $700 \%$ !

The major criticism of the individual consultant has been mentioned above - e.g., the danger of imposing the idiosyncratic values of the consultants and promoting the illusion that a single person, rather than everyone in the institution, has both important knowledge and responsibility concerning optimum moral decision making. In addition, individual consultants should have considerable expertise and experience, something not available in many institutional settings or communities.

A small team, consisting, for example, of a physician, nurse, and social worker is a third choice. A small team can have the best of both worlds - the virtues of quick response, direct gathering of data, more than one point of view, and clear accountability.

In my view, the best choice, if possible, is performing CEC with a small team in conjunction with a full ethics committee. For example, a team of three persons could do the consults and present them retrospectively to the full committee at a regularly scheduled monthly meeting. This would offer the opportunity for peer review, greater institutional ownership of CEC and education for committee members not involved in the original consult. In cases where the team felt uncomfortable, it could request an emergency meeting of the full committee for prospective review of the case. Committee members could rotate their service as members of the smaller team, allowing for even greater involvement and education.

\section{ConcLusion}

CEC is a relatively new endeavor that has been largely limited to North America where it has been shaped by 
that region's unique legal, social, and cultural characteristics and development. This experience might serve as example but should not provide an exact model for CEC in other countries or cultures. In this essay, I have attempted to set out some of the operational characteristics of and choices facing CEC in the United States of America. I do believe that whatever the culture or community, modern high-technology medicine poses dif- ficult value choices. Whatever, the nature of information sharing and decision making, some people in the system struggle to do the right thing when they are not sure exactly what that is. In liberal, pluralistic democracies, the answers can not come from religious or political authorities. They must be the result of public discussion, education, and compromise. To this end, CEC can make an important contribution.

\section{NOTAS}

1 The American Society of Bioethics and Humanities. Core competencies for health care ethics consultation: The report of the American Society of Bioethics and Humanities, Greenview, IL: The American Society of Bioethics and Humanities; 1998.

2 Youngner, S. J.; D. L. Jackson, et al. (1983): "A national survey of hospital ethics committees", Crit Care Med 11(11): 902-5.

Recibido: 30 de junio de 2007

Aceptado: 30 de septiembre de 2007
3 Fox, E.; S. Myers, et al. (2007): "Ethics Consultations in United States Hos- pitals: A National Survey", American Journal of Bioethics 7(2): 13-25.

4 Agich, J. G. Y Youngner, S. J. (1991): For experts only? access to hospital ethics committees. Hastings Cent Rep 21(5): 17-25.

5 Rushton, C.; Youngner, S. J. y Skeel, J.: "Models for Ethics Consultation: Individual, Team, or Committee?", in: Aulisio, M. P.; Arnold, R. M. y Youngner, S. J. (Eds.): Ethics Consultation: From Theory to Practice. Johns Hopkins University Press 2003; 88-95. 